\title{
Photodegradation assessment of amisulpride, doxepin, haloperidol, risperidone, venlafaxine, and zopiclone in bulk drug and in the presence of excipients
}

\author{
Anna Maślanka ${ }^{1} \cdot$ Paweł Żmudzki $\cdot$ Marek Szlósarczyk ${ }^{1} \cdot$ Przemysław Talik $^{1} \cdot$ Urszula Hubicka $^{1}$
}

Received: 9 October 2019 / Accepted: 25 February 2020 / Published online: 8 April 2020

(c) The Author(s) 2020

\begin{abstract}
Photostability of amisulpride, doxepin, haloperidol, risperidone, venlafaxine, and zopiclone in APIs and powdered tablets during exposure to UVA irradiation was studied. In order to evaluate the photodegradation process an ultrahigh performance liquid chromatography method coupled with tandem mass spectrometry (UHPLC-MS/MS) was developed and validated. It was found that the photodegradation of the studied compounds depends on the type of drug and co-existing excipients. Different percentage of photodegradation of the studied drugs was observed, and therefore amisulpride decomposed at $2.63 \%$ in bulk drug and at $5.74 \%$ in pharmaceutical preparation, doxepin: $29 \%$ and $72.38 \%$, haloperidol: $3.71 \%$ and $26.20 \%$, risperidone: $7.13 \%$ and $12.86 \%$, venlafaxine: $38.59 \%$ and $4.22 \%$, zopiclone: $18.62 \%$ and $31.42 \%$ respectively, after 114 days of UVA irradiation. In addition, kinetic evaluation of the photodegradation process was performed by determining the order of reaction, reaction rate constant $k$ and time $t_{0.1}$ and $t_{0.5}$. The photodegradation products of studied drugs were identified, and their fragmentation pathways, derived from MS/MS data, were proposed. The photostability testing is an integral part of the drug stability assessment to ensure quality, efficacy and safety of the formulated products during manufacturing process, storage as well as normal use.
\end{abstract}

\section{Graphic abstract}

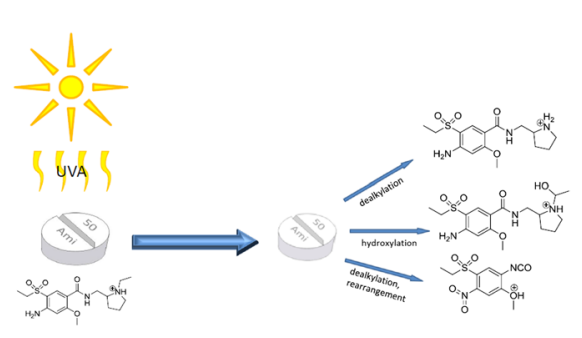

Keywords Excipients $\cdot$ Kinetics $\cdot$ Photodegradation $\cdot$ Solid state $\cdot$ UHPLC-MS/MS

\section{Introduction}

Anna Maślanka

anna.maslanka@uj.edu.pl

1 Department of Inorganic and Analytical Chemistry, Jagiellonian University, Collegium Medicum, Medyczna 9, 30-688 Kraków, Poland

2 Department of Medicinal Chemistry, Jagiellonian University, Collegium Medicum, Medyczna 9, 30-688 Kraków, Poland
One of numerous factors influencing stability of the drug, is light which initiates the process of photochemical conversion, leading to changes in the chemical structure of the exposed compound. The problem of interaction between light and pharmaceutical products is important in the drug formulation technology during both, technological processes and storage as well. Irradiation can lead to the reduction or loss of drug activity, as well as formation of toxic products 
of photodegradation. Therefore, photostability testing is an integral part of the assessment of the drug stability, which is important at the stage of drug development and its registration aiming at ensuring its safety and efficacy [1-5].

Active pharmaceutical ingredients (APIs) may be directly or indirectly exposed to radiation. Direct photochemical reactions occur when API degradation is the result of direct light excitation of its molecules. The substance will only degrade if it comes in contact with radiation of an appropriate wavelength. In the case of an indirect (sensitized) photoreaction there is a transfer of excitation energy to a molecule (e.g. API) other than the compound which initially absorbs the radiation. The compound that absorbs the radiation, the photosensitizer (e.g. excipient, impurity), is initially transformed from its ground state (singlet state) into a relatively long-lived excited triplet state. The excited triplet state can mediate a photosensitized reaction due to the long lifetime and bi-radical nature with unpaired electron spins [6]. Therefore, both the excipients and the type of preparation could influence the photoreactivity of the drug substance.

The purpose of this work was to study the photostability of selected drugs in APIs and powdered tablets during exposure to UVA irradiation. Furthermore, we studied the impact of excipients present in tablets on the photodegradation process. In order to evaluate the photodegradation process we have developed and validated an ultrahigh performance liquid chromatography method coupled with tandem mass spectrometry (UHPLC-MS/MS) for the determination of APIs and their phodegradation products. In addition, the kinetic evaluation of the photodegradation process was carried out and photodegradation products have been identified. The investigations have been performed on the group of drugs belonging to the central nervous system agents representing different structural groups. The selection of drugs was based on their properties, availability and photodegradation process. In the study the following drugs were used: amisulpride, doxepin, haloperidol, risperidone, venlafaxine, zopiclone which undergo photodegradation process.

Amisulpride (AMI, $(R S)$-4-amino- $N$-[(1-ethylpyrrolidin2-yl)methyl]-5-ethylsulfonyl-2-methoxy-benzamide) is an atypical neuroleptics used in the treatment of schizophrenia, dysthymia, and mild-moderate depression. Doxepin (DOX, 11-(3-dimethylaminopropylidene)dibenzo[b,e]oxepin), belongs to the group of tricyclic antidepressants (TCAs), oxepin derivatives. It has an anxiolytic and sedative effect. Haloperidol (HAL, 4-[4-(4-chloro)-4-hydroxy-1piperidinyl]-1(4-fluorophenyl)-1-butanone), is a derivative of butyrophenone. It has a strong antipsychotic and sedative effect. Risperidone (RIS, 3-[2-[4-(6-fluoro-1,2-benzoxazol3-yl)piperidin-1-yl]ethyl]-2-methyl- $4 H, 6 H, 7 H, 8 H, 9 H$ pyrido[1,2-a]pyrimydin-4-one), is a benzoxazole derivative. It is a second generation anti-psychotic drug, used in the treatment of schizophrenia. Venlafaxine (VEN,
$(R S)$-1-[2-(dimethylamino)-1-(4-methoxyphenyl)ethyl]cyclohexanol) is a third generation antidepressant drug, it belongs to the group of selective serotonin-norepinephrine reuptake inhibitors (SNRIs). Zopiclone (ZOP, $(R S)-6-(5-$ chloropyridin-2-yl)-7-oxo-6,7-dihydro-5H-pyrrolo[3,4- $b$ ]pyrazin-5-yl-4-methylpiperazine-1-carboxylate) is a hypnotic, ciclopirolone derivative. It has hypnotic, sedative, anxiolytic effect.

Photostability of some of the investigated drugs is a subject of a few research publications: and so, by UHPLC method coupled with mass detection, AMI degradation products in methanol solutions were identified under the influence of UVA radiation [7]. For the identification of photodegradation products of aqueous DOX solutions, TLC with densitometric detection was used [8, 9]. Photostability of VEN in aqueous solutions was evaluated using LC/ MS method [10], and the effect of UVA on the stability of solutions containing ZOP was evaluated by capillary electrophoresis [11].

In the available literature, no data on the photodegradation studies in solid state of the drugs we selected were found.

\section{Results and discussion}

\section{Method validation}

UHPLC-MS/MS used in the photostability study of AMI, DOX, HAL, RIS, VEN, and ZOP was validated by evaluation of its specificity, accuracy, precision, linearity range, limit of detection, and limit of quantification. The developed method provides satisfactory separation of the tested pharmaceutical substances from their photodegradation products as evidenced by the values of resolution factor $R_{\mathrm{S}}$ calculated based on equation $R_{\mathrm{s}}=2\left(t_{\mathrm{R} 2}-t_{\mathrm{R} 1}\right) /\left(W_{1}+W_{2}\right)$ where $t_{\mathrm{R} 1}$, $t_{\mathrm{R} 2}$-retention time for peak 1 and 2 , respectively; $W_{1}, W_{2}$ peak widths at the base [s] for peak 1 and 2, respectively.

The main peak purity was examined with MS spectra using CODA algorithm (Waters Corporation, Milford, MA, USA). The investigated MS spectra uniquely contained signals corresponding to the examined substances and solvent.

Recovery percent of the tested components shown as average values for three concentration levels was satisfactory, and ranged between 97.08 and $104.17 \%$. High precision determined for three concentration levels was confirmed by the RSD values ranging from 0.06 to $2.95 \%$.

Linearity was maintained over a concentration range, from 0.306 to $2.040 \mathrm{mg} \mathrm{cm}^{-3}$ for AMI, from 0.300 to $2.00 \mathrm{mg} \mathrm{cm}^{-3}$ for DOX, from 0.321 to $1.926 \mathrm{mg} \mathrm{cm}^{-3}$ for $\mathrm{HAL}$, from 0.214 to $2.140 \mathrm{mg} \mathrm{cm}^{-3}$ for RIS, from 0.204 to $1.836 \mathrm{mg} \mathrm{cm}^{-3}$ for VEN, and from 0.315 to $2.100 \mathrm{mg} \mathrm{cm}^{-3}$ for ZOP. Linear determination coefficient $R^{2}$ did not specify 
Table 1 Linear and quadratic equation of examined substances

\begin{tabular}{|c|c|c|c|c|}
\hline Substance & $\begin{array}{l}\text { Linear equation } \\
(p)\end{array}$ & $\begin{array}{l}\text { Quadratic equation } \\
(p)\end{array}$ & $R^{2}$ & $\begin{array}{l}\text { Mandel's test } \\
(p)\end{array}$ \\
\hline \multirow[t]{2}{*}{ AMI } & $P=13,776,164 c+1,132,199$ & $P=-1,119,232 c^{2}+116,327,583 c+76,297$ & $0.9991^{*}$ & $\begin{array}{l}33.27 \\
(0.000)\end{array}$ \\
\hline & $(0.000)$ & $(0.000)$ & & \\
\hline \multirow[t]{2}{*}{ DOX } & $P=11,480,140 c+913,098$ & $P=-1,281,012 c^{2}+1,434,3095 c-248,501$ & $0.9991^{*}$ & $\begin{array}{l}61.49 \\
(0.000)\end{array}$ \\
\hline & $(0.000)$ & $(0.000)$ & & \\
\hline \multirow[t]{2}{*}{ HAL } & $P=7,927,836 c-165,091$ & $P=-307,348 c^{2}+8,585,562 c-423,473$ & 0.9982 & $\begin{array}{l}3.863 \\
(0.075)\end{array}$ \\
\hline & $(0.000)$ & $(0.075)$ & & \\
\hline \multirow[t]{2}{*}{ RIS } & $P=8,378,351 c-52,715$ & $P=1,31,629 c^{2}+8,063,578 c+83,937$ & 0.9996 & $\begin{array}{l}4.206 \\
(0.061)\end{array}$ \\
\hline & $(0.000)$ & $(0.062)$ & & \\
\hline \multirow[t]{2}{*}{ VEN } & $P=3,598,226 c+126,161$ & $P=-94,150 c^{2}+3790292 c+54,235$ & $0.9998^{*}$ & $\begin{array}{l}9.558 \\
(0.010)\end{array}$ \\
\hline & $(0.000)$ & $(0.010)$ & & \\
\hline \multirow[t]{2}{*}{ ZOP } & $P=7,816,537 c+519,263$ & $P=-46,535 c^{2}+7,925,741 c+472,739$ & $0.9990^{*}$ & $\begin{array}{l}0.172 \\
(0.685)\end{array}$ \\
\hline & $(0.000)$ & $(0.005)$ & & \\
\hline Substance & $\begin{array}{l}\text { SW test } \\
(p)\end{array}$ & DW test & $\begin{array}{l}\text { LM test } \\
(p)\end{array}$ & $\begin{array}{l}\text { Bartlett test } \\
(p)\end{array}$ \\
\hline AMI & $\begin{array}{l}0.921 * \\
(0.181)\end{array}$ & $1.735^{*}$ & - & $\begin{array}{l}0.042 \\
(0.837)^{*}\end{array}$ \\
\hline DOX & $\begin{array}{l}0.974 * \\
(0.903)\end{array}$ & $1.434^{*}$ & $\begin{array}{l}1.087 \\
(0.297)^{*}\end{array}$ & $\begin{array}{l}3.027 \\
(0.082)^{*}\end{array}$ \\
\hline HAL & $\begin{array}{l}0.910 \\
(0.156)\end{array}$ & 1.415 & - & $\begin{array}{l}0.003 \\
(0.955)\end{array}$ \\
\hline RIS & $\begin{array}{l}0.929 \\
(0.241)\end{array}$ & 1.194 & $\begin{array}{l}2.295 \\
(1.130)\end{array}$ & $\begin{array}{l}0.462 \\
(0.497)\end{array}$ \\
\hline VEN & $\begin{array}{l}0.946^{*} \\
(0.501)^{*}\end{array}$ & $1.848^{*}$ & - & $\begin{array}{l}0.181^{*} \\
(0.673)^{*}\end{array}$ \\
\hline ZOP & $\begin{array}{l}0.941 \\
(0.275)^{*}\end{array}$ & $1.370^{*}$ & $\begin{array}{l}1.480 \\
(0.224)^{*}\end{array}$ & $\begin{array}{l}1.189 \\
(0.275)^{*}\end{array}$ \\
\hline
\end{tabular}

* For quadratic equation; $P$, peak surface area $\left[\mathrm{mm}^{2}\right] ; c$, concentration of solution $\left[\mathrm{mg} \mathrm{cm}^{-3}\right] ; R^{2}$, coefficient of determination; $(p), p$ significance; SW, Shapiro-Wilk; DW, Durbin-Watson; LM, Lagrange multiplier test

clearly the linearity of the calibration method [12]. Therefore, to assess the linearity, Mandel's test was used. Comparative results of linear and quadratic fit of the studied drugs indicate linear fit of calibration curves for HAL and RIS. The $p$-values indicate the significance of the slopes and nonsignificance of the intercepts. In other cases, quadratic fit was obtained. The results of Mandel's test $(p=0.685)$ indicate equal contribution of linear and quadratic fit for ZOP calibration, however due to the statistical significance of the intercept in the linear model, quadratic model was selected. The normality of residuals distribution was confirmed by the Shapiro-Wilk test. The results of the Durbin-Watson (D-W) test showed no significant autocorrelation of random components, except for DOX, RIS, and ZOP. For the abovementioned drugs, $\mathrm{D}-\mathrm{W}$ test did not decide on the presence or absence of autocorrelation, therefore Lagrange multiplier test was performed. The results of this test indicate no significant autocorrelation of random components in the selected models. Constant variance of random components in the proposed fits was checked using Bartlett test. The obtained results indicate the presence of constant variance in all cases ( $p$-value $>0.05)$ (Table 1).

Sensitivity of the developed methods was estimated, LOD was at $0.087 \mathrm{mg} \mathrm{cm}^{-3}$ for AMI, $0.068 \mathrm{mg} \mathrm{cm}^{-3}$ for DOX, $0.077 \mathrm{mg} \mathrm{cm}^{-3}$ for HAL, $0.046 \mathrm{mg} \mathrm{cm}^{-3}$ for RIS, $0.024 \mathrm{mg} \mathrm{cm}^{-3}$ for VEN, and $0.095 \mathrm{mg} \mathrm{cm}^{-3}$ for ZOP, LOQ estimated at $0.264 \mathrm{mg} \mathrm{cm}^{-3}, 0.205 \mathrm{mg} \mathrm{cm}^{-3}, 0.233 \mathrm{mg} \mathrm{cm}^{-3}$, $0.139 \mathrm{mg} \mathrm{cm}^{-3}, 0.072 \mathrm{mg} \mathrm{cm}^{-3}$, and $0.288 \mathrm{mg} \mathrm{cm}^{-3}$, respectively. 
Fig. 1 Chromatograms of AMI, DOX, and HAL recorded after 114 days of irradiation with UVA. a Irradiation of bulk drug, $\mathbf{b}$ irradiation of powdered tablets
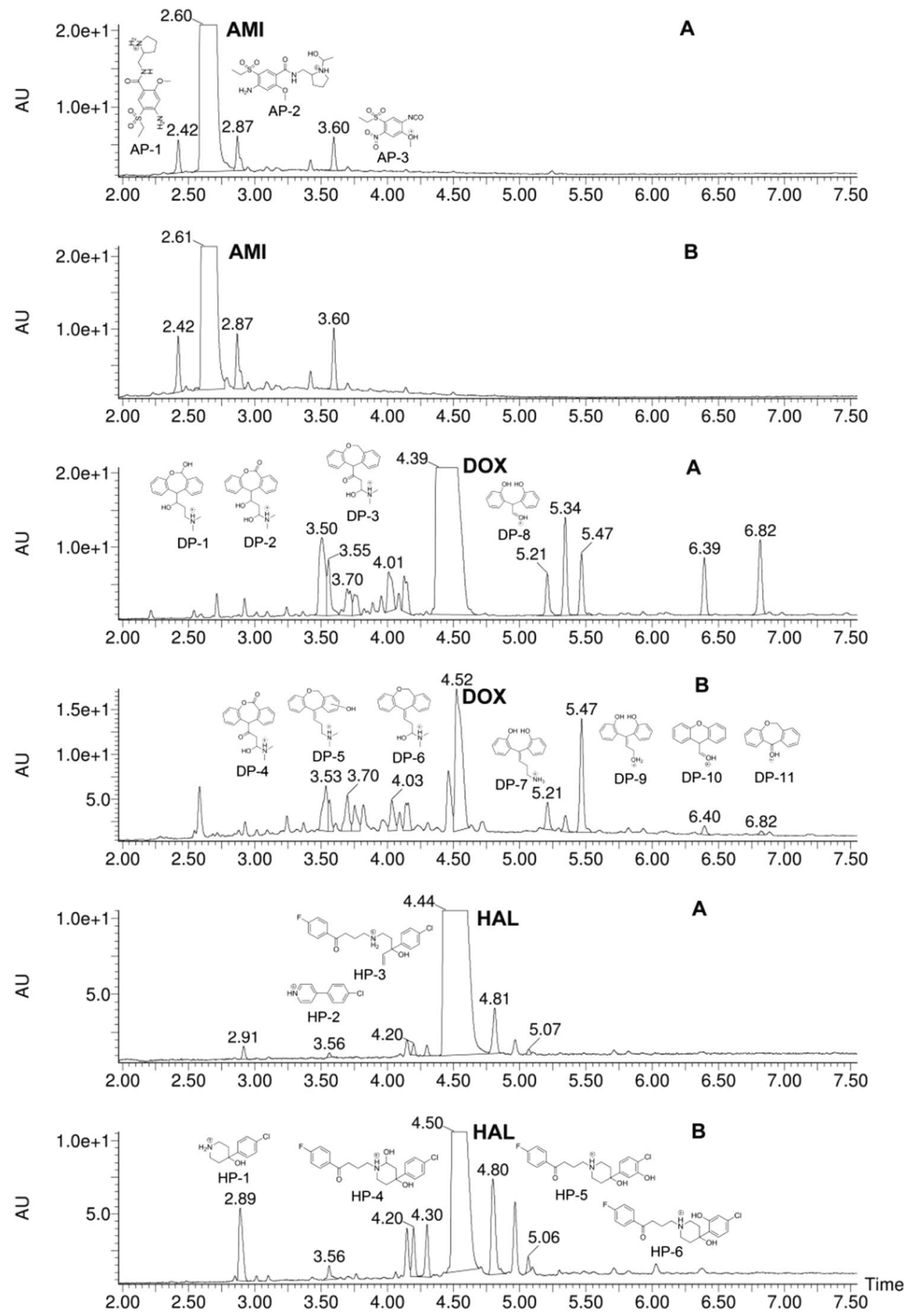

\section{Photostability study of the analyzed substances in bulk drug and in powdered tablets}

Studies of the effect of UVA on AMI, DOX, HAL, RIS, VEN, and ZOP in bulk drug and in powdered tablets demonstrated, that they undergo photodegradation, which proceeds at different speeds, depending on the type of API and excipients in drug dosage form. In the registered chromatograms, differences in the number of additional peaks as well as in retention times $\left(t_{\mathrm{R}}\right)$ were observed. Different decomposition rate of a given substance in bulk drug and in a pharmaceutical preparation was reported. In most cases, these differences also include the number of resulting products occurring due to the photodegradation process. However, no changes were observed during irradiation of dark control samples.

As a result of AMI decomposition in both, bulk drug and pharmaceutical preparation, three products were formed: AP-1, AP-2, and AP-3, in the case of DOX eleven products 
Fig. 2 Chromatograms of RIS, VEN, and ZOP recorded after 114 days of irradiation with UVA. a Irradiation of bulk drug, $\mathbf{b}$ irradiation of powdered tablets
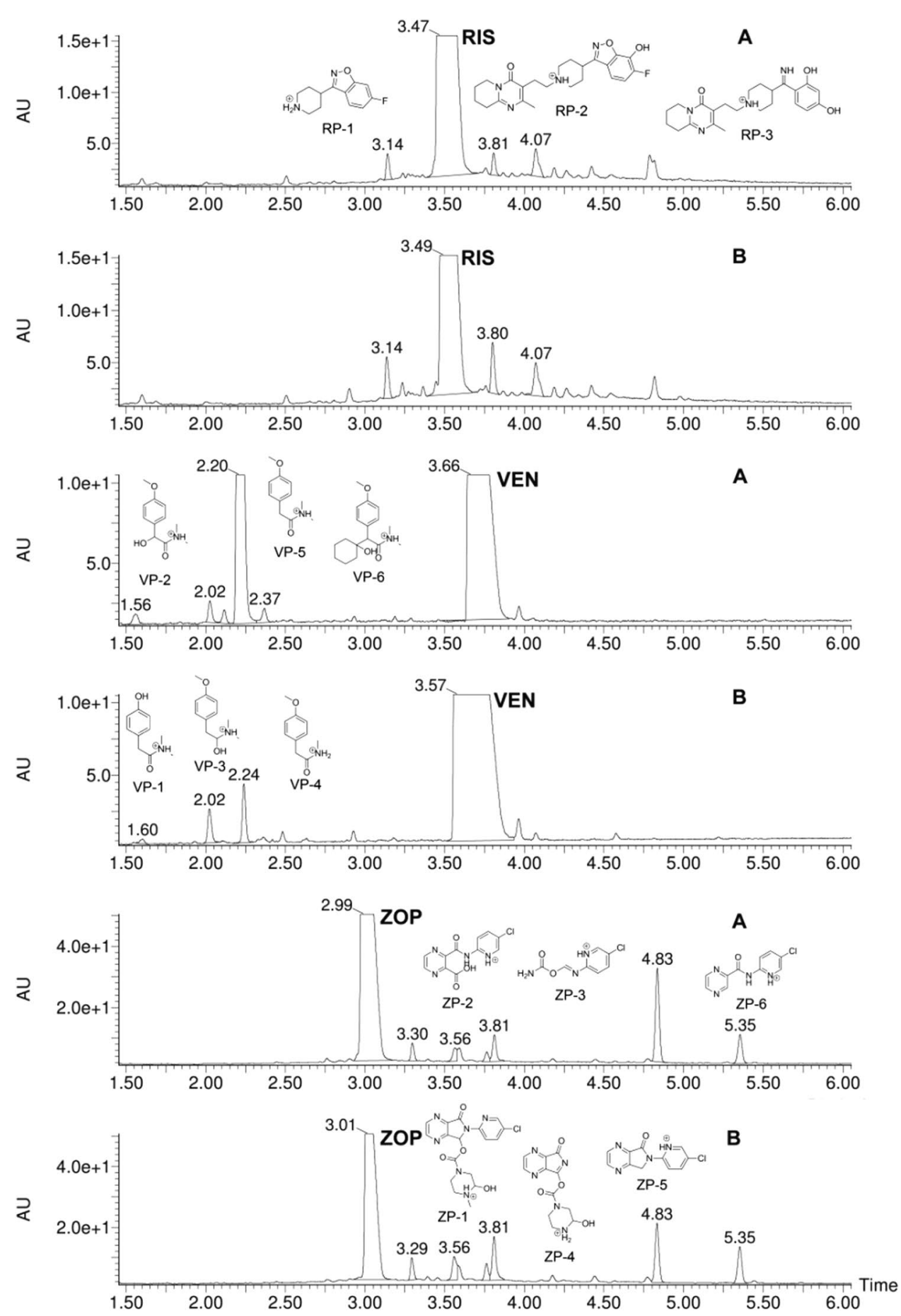

(DP-1-DP-11) were identified in both irradiated samples. Under the influence of UVA six products were formed in the preparation containing HAL: HP-1-HP-6, five in the irradiated substance: HP-1, HP-2, HP-3, HP-5, and HP-6 (Fig. 1).

Both irradiated RIS samples decomposed into three products: RP-1, RP-2, and RP-3. VEN in bulk drug decomposed into six products: VP-1-VP-6, whereas in the pharmaceutical preparation only into four VP-1, VP-3, VP-5, and VP-6. Six products of photodegradation were formed in the case of
ZOP, both in bulk drug and in the pharmaceutical preparation: ZP-1-ZP-6 (Fig. 2).

Different percentage of photodegradation of the studied drugs was observed, and therefore AMI decomposed at $2.63 \%$ in bulk drug and at $5.74 \%$ in pharmaceutical preparation, DOX: $29 \%$ and $72.38 \%$, HAL: $3.71 \%$ and $26.20 \%$, RIS: $7.13 \%$ and $12.86 \%$, VEN: $38.59 \%$ and $4.22 \%$, ZOP: $18.62 \%$ and $31.42 \%$ respectively, after 114 days of UVA irradiation with estimated standard deviation calculated as uncertainty 


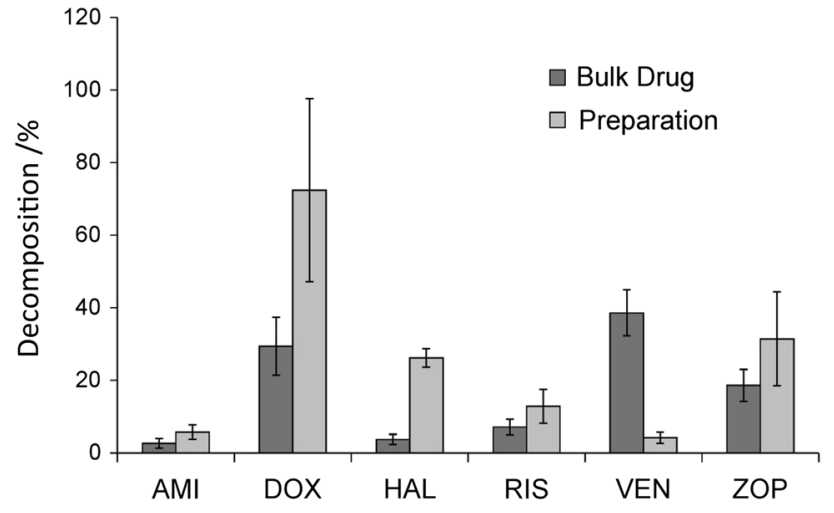

Fig. 3 Comparison of the decomposition percentage of the studied drugs $( \pm \mathrm{SD})$ in a bulk drug and in pharmaceutical preparation

from periods $(12,26,44,56,79,91$, and 114 days) on the assumption of first order kinetics (Fig. 3). In majority of the studied drugs, higher decomposition occurs in powdered tablets than in bulk drug, except for VEN, for which the situation is reversed: in bulk drug, photodegradation occurs faster than in the pharmaceutical preparation.

Differences in photodegradation between the API and the pharmaceutical preparation can be justified by the presence of excipients in the form of drug. The effect of UV radiation on these substances is diverse: they can be inhibitors of photochemical reactions, be susceptible to attack of free radicals and inhibit the decomposition of the active substance, they can undergo photodegradation, they can also be a source of peroxides and also participate in free radical reactions [13, 14].

Increased decomposition in the tablets as compared to a bulk drug may be caused by the presence of excipients, particularly $\mathrm{TiO}_{2}$ exhibiting photocatalytic properties [15] associated with absorption of radiation. As a result, the energy of photons absorbed by $\mathrm{TiO}_{2}$ can be converted into chemical energy leading to the formation of hydroxyl radicals (e.g. from water vapor). In the case of RIS and ZOP, the irradiated tablet mass contained $\mathrm{TiO}_{2}$.

Among the tested drugs AMI, DOX, VEN, and HAL preparations do not contain $\mathrm{TiO}_{2}$ in powdered mass of the tablet. In terms of AMI tablets, photodegradation occurs to a lesser degree. As mentioned above, VEN in bulk drug decomposes to a greater extent as compared to pharmaceutical preparation. Taking into account slight differences in the composition of excipients, which relate to the presence of the Eudragit RS 100 copolymer, one can assume that this substance may weaken the direct effect of UV radiation. In the checked literature, publications describing the research showing the protective action of Eudragit against UV-VIS radiation on pantoprazole [16, 17], ranitidine [18], clotrimazole [19], and microorganisms Spodoptera frugiperda multiple nucleopolyhedrovirus $[20,21]$ were found.

In addition, among the tested pharmaceutical preparations DOX, RIS, and ZOP contained in their composition talc, which has nucleating properties and can increase the light transmission of the powdered tablet mass, similar to nucleated polymers [22, 23].

The observed differences in photodegradation processes occurring in the studied drugs may also be associated with diverse chemical structures of individual substances.

\section{Kinetics study}

Changes in the concentration of the studied drugs occurring during UVA irradiation were determined in accordance with first-order reaction kinetics (Fig. 4) calculating the reaction rate constant $k$, degradation half-times $t_{0.5}$ and $t_{0.1}$, after which $50 \%$ and $10 \%$ of initial substances undergo degradation, respectively.

The calculated values of reaction rate constants of photodegradation in the case of the most studied drugs have different values and vary from the lowest for AMI and HAL to the highest for DOX in bulk drug, and in pharmaceutical preparations from AMI and VEN to DOX, respectively (Table 2).

\section{Identification of degradation products}

The structures of photodegradation products of AMI, DOX, HAL, RIS, VEN, and ZOP were proposed on a basis of UHPLC/MS analysis supported with fragmentation patterns obtained from MS/MS experiments. The proposed degradation products are shown in Figs. 1, 2 with parameters in Table 3.

In case of AMI it seems that the photodegradation mainly involved dealkylation of pyrrolidine moiety (AP1) or hydroxylation of ethyl substituent of nitrogen atom of pyrrolidine moiety (AP-2). Additionally one product of dealkylation of nitrogen atom of amide moiety with subsequent rearrangement was observed (AP-3).

In case of DOX the CAD experiments suggest that the photodegradation process mainly involved hydroxylation of propylidenyl chain (DP-1-DP-4, DP-6) and/or hydratation of double bond between propylidene chain and oxepine ring (DP-1 and DP-2). In case of products DP-1, DP-2, and DP-4 it seems that the photodegradation involved also oxidation of oxepine ring in close vicinity to oxygen atom. It seems that only in case of DP-5 oxidation took place in one of the phenyl rings. Further oxidation of DOX led to oxepine ring opening (DP-7-DP-9), demethylation of amine moiety (DP-7) and degradation of propylidene chain (DP-8-DP-11). Product DP-10 seems to be intramolecular condensation product of DP- 8 . 

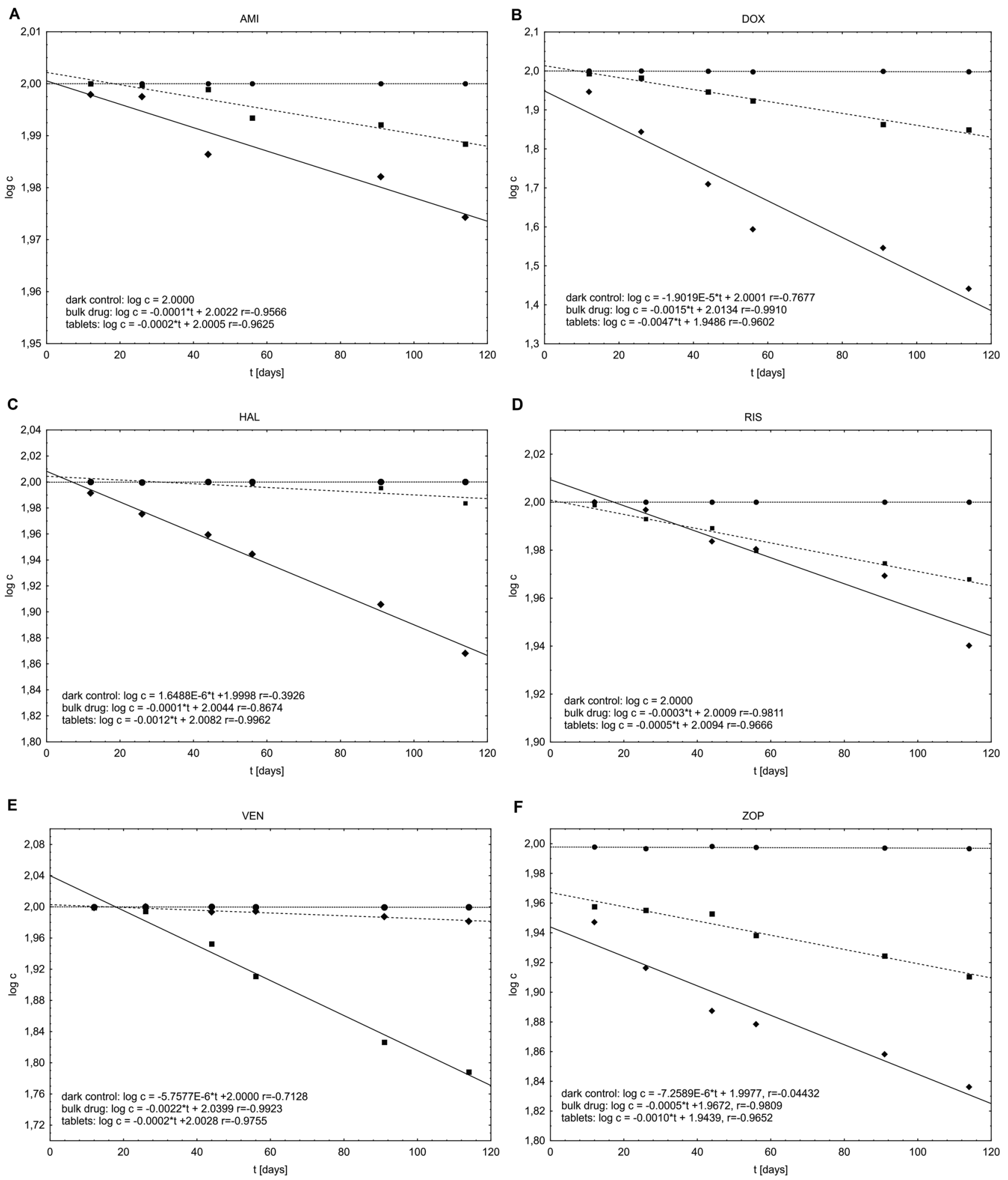

Fig. 4 The dependence of $\log c=f(t)$ for: $\mathbf{a}$ amitriptiline, $\mathbf{b}$ doxepine, $\mathbf{c}$ haloperidol, $\mathbf{d}$ risperidon, $\mathbf{e}$ venlafaxine, and $\mathbf{f}$ zopiclon photodegradation in the dark control samples (dot line), bulk drug (dash line) and tablets (solid line)

In case of HAL the photodegradation process seems to involve dealkylation of nitrogen atom of piperidine ring (HP-1) with subsequent dehydrogenation (HP-2), opening of piperidine ring (HP-3), its hydroxylation (HP-4), or hydroxylation of phenyl ring of 4-(4-chlorophenyl)-piperidin-4-ol moiety (HP-5 and HP-6). 
Table 2 Kinetic parameters of UVA photodegradation

\begin{tabular}{lllrrl}
\hline $\begin{array}{l}\text { Substance } \\
\text { name }\end{array}$ & $\begin{array}{l}\text { Drug } \\
\text { form }\end{array}$ & $k /$ day $^{-1}$ & $t_{0.5} /$ days & $t_{0.1} /$ days & $\begin{array}{l}\text { Correlation } \\
\text { coefficient } r\end{array}$ \\
\hline AMI & Bulk drug & $2.303 \cdot 10^{-4}$ & 3009.12 & 457.23 & -0.9566 \\
& Tablets & $4.606 \cdot 10^{-4}$ & 1504.56 & 228.61 & -0.9625 \\
DOX & Bulk drug & $3.454 \cdot 10^{-3}$ & 200.61 & 30.48 & -0.9910 \\
& Tablets & $1.080 \cdot 10^{-2}$ & 64.05 & 9.73 & -0.9602 \\
\multirow{2}{*}{ HAL } & Bulk drug & $2.303 \cdot 10^{-4}$ & 3009.12 & 457.23 & -0.8674 \\
& Tablets & $2.764 \cdot 10^{-3}$ & 250.76 & 38.10 & -0.9962 \\
RIS & Bulk drug & $6.909 \cdot 10^{-4}$ & 1003.04 & 152.41 & -0.9811 \\
& Tablets & $1.151 \cdot 10^{-3}$ & 601.82 & 91.44 & -0.9666 \\
VEN & Bulk drug & $5.067 \cdot 10^{-3}$ & 136.78 & 20.78 & -0.9923 \\
& Tablets & $4.606 \cdot 10^{-4}$ & 1504.56 & 228.61 & -0.9755 \\
ZOP & Bulk drug & $1.151 \cdot 10^{-3}$ & 601.82 & 91.44 & -0.9809 \\
& Tablets & $2.303 \cdot 10^{-3}$ & 300.91 & 45.72 & -0.9652 \\
\hline
\end{tabular}

The photodegradation of RIS seems to involve dealkylation of nitrogen atom of piperidine ring (RP-1), hydroxylation of phenyl ring of benzo[ $d]$ isoxazole moiety (RP-2), or substitution of fluorine at the benzo[ $[d]$ isoxazole moiety with hydroxyl group (RP-3). Additionally for RP-3 opening of the isoxazole ring was observed.

The photodegradation of VEN seems to involve oxidation of methylene group in close vicinity to the nitrogen atom (all major products, VP-1-VP-6) and $\mathrm{C}-\mathrm{C}$ bond breaking between cyclohexyl moiety and ethylene chain (VP-1-VP-5). Additionally for product VP-2 further oxidation of ethylene chain was observed, and for products VP-1 and VP-4 demethylation of oxygen (VP-1) or nitrogen (VP4) atom took place.

In case of ZOP the photodegradation process seems to involve degradation of pyrrolone ring (ZP-2, ZP-3, ZP-6), hydroxylation of piperidine moiety (ZP-1 and ZP-4), loss of (4-methylpiperazinyl)carboxyl moiety or its fragment (ZP2, ZP-3, ZP-5, and ZP-6). For ZP-4 loss of chloropyridinyl moiety was observed.

\section{Conclusions}

The developed UHPLC method meets the criteria of validation and may be used for the determination of AMI, DOX, HAL, RIS, VEN, and ZOP in the presence of their photodegradation products. Photodegradation of the studied substances follows first-order kinetics. It was found, that most of the investigated drugs decompose much faster in powdered tablets than in bulk drug substance, except for VEN, which decomposes tenfold faster in bulk drug than in the form of tablets. Calculated values of the kinetic parameters $\left(k, t_{0.1}\right.$, and $t_{0.5}$ ) show that the quickest decomposition is observed for DOX in both, substance as well as in pharmaceutical preparation, and the slowest decomposition is observed for AMI and HAL substances and powdered tablets containing AMI and VEN.

Using mass spectrometry, photodegradation products were identified followed by the establishment of their structure.

\section{Experimental}

Amisulpride (99.9\%), doxepin hydrochloride (99.5\%), haloperidol $(99.9 \%)$, risperidone $(99.7 \%)$, venlafaxine hydrochloride (99.8\%), zopiclone (99.4\%) (LGC Promochem [Ltd.], Poland). Methanol and acetonitrile of analytical grade (Chempur, Piekary Śląskie, Poland). Acetonitrile of LC-MS grade and formic acid (98\%) (Sigma-Aldrich), water for HPLC from HLP 5 generator (HYDROLAB Poland).

\section{Pharmaceutical preparations}

Solian-tablets containing $200 \mathrm{mg}$ of amisulpride (Sanofi Aventis, Paris, France). Excipients: sodium starch glycolate (type A), lactose monohydrate, microcrystalline cellulose, hypromellose, magnesium stearate.

Doxepin-hard capsules containing $10 \mathrm{mg}$ of doxepin hydrochloride (Pliva Cracow, Poland). Excipients: lactose monohydrate, maize starch, gelatinised starch, talc, magnesium stearate, Hard capsule shell: gelatin, titanium dioxide, erythrosine, brilliant blue.

Haloperidol WZF-tablets containing $5 \mathrm{mg}$ of haloperidol (Warsaw Pharmaceutical Works Polfa, Warsaw, Poland). Excipients: lactose monohydrate, microcrystalline cellulose, colloidal hydrated silica, croscarmellose sodium, magnesium stearate.

Risperdal-coated tablets containing $4 \mathrm{mg}$ of risperidone (Janssen-Cilag, Val-de-Reuil, France). Tablet core: lactose, maize starch, microcrystalline cellulose, hypromellose, magnesium stearate, colloidal anhydrous silica, sodium lauryl sulfate. Tablet coating: propylene glycol, titanium dioxide, talc, indigo carmine, quinoline yellow.

Venlectine-prolonged-release hard capsules containing $37.5 \mathrm{mg}$ of venlafaxine hydrochloride (ICN Polfa Rzeszów, Rzeszów, Poland). Tablet core: hypromellose, eudragit RS 100, sodium lauryl sulfate, magnesium stearate. Tablet coating: eudragit RS 100. Capsule shell: titanium dioxide, gelatin.

Senzop - coated tablets containing $7.5 \mathrm{mg}$ of zopiclone (Jelfa, Jelenia Gora, Poland). Tablet core: calcium hydrogen phosphate dihydrate, lactose monohydrate, maize starch, sodium starch glycolate (type A), magnesium stearate. Tablet coating: hypromellose, propylene glycol, talc, titanium dioxide. 
Table 3 Proposed products of photodegradation of amisulpride, dexepine, haloperidol, risperidone, venlafaxine, and zopiclone

\begin{tabular}{|c|c|c|c|}
\hline Product id & RT & {$[\mathrm{M}+\mathrm{H}]+$} & Fragmentation ions \\
\hline AP-1 & 2.42 & 342.2 & $84.1,101.1,127.1,214.1,242.1$ \\
\hline AMI & 2.61 & 370.2 & $84.1,112.1,129.1,155.1,214.1,242.1$ \\
\hline AP-2 & 2.87 & 386.2 & $84.1,110.1,128.1,145.1,171.1,214.1,242.1$ \\
\hline AP-3 & 3.60 & 287.0 & 242.0 \\
\hline DP-1 & 3.50 & 314.2 & $58.1,72.1,102.1,107.0,205.1,223.1,233.1,251.1,296.2$ \\
\hline DP-2 & 3.55 & 328.2 & $58.1,219.1,264.1,292.1,310.1$ \\
\hline DP-3 & 3.70 & 312.2 & $58.1,88.1,98.1,195.1,249.1,294.1$ \\
\hline DP-4 & 3.75 & 326.1 & $58.1,88.1,98.1,209.1,247.1,262.1,281.1,290.1,308.1$ \\
\hline DP-5 & 4.01 & 296.2 & $58.1,107.0,223.1,251.1$ \\
\hline DP-6 & 4.13 & 296.2 & $58.1,88.1,107.0,233.1,278.2$ \\
\hline DOX & 4.39 & 280.2 & $58.1,72.1,84.1,107.0,207.1,221.1,235.1$ \\
\hline DP-7 & 5.21 & 256.1 & $119.0,162.1,193.1,211.1$ \\
\hline DP-8 & 5.34 & 229.1 & $135.0,193.1,211.1$ \\
\hline DP-9 & 5.47 & 243.1 & $149.1,225.1$ \\
\hline DP-10 & 6.39 & 211.1 & $183.1,193.1$ \\
\hline DP-11 & 6.82 & 211.1 & $77.0,105.0,183.1$ \\
\hline HP-1 & 2.89 & 212.1 & 194.1 \\
\hline HP-2 & 3.56 & 190.0 & - \\
\hline HP-3 & 4.20 & 376.2 & $123.0,165.1,358.1$ \\
\hline HP-4 & 4.30 & 392.1 & 123.0, 165.1, 192.1, 210.1, 356.1, 374.1 \\
\hline HAL & 4.50 & 376.2 & $123.0,165.1,358.1$ \\
\hline HP-5 & 4.80 & 392.1 & $123.0,165.1,374.1$ \\
\hline HP-6 & 5.06 & 392.1 & $123.0,165.1,374.1$ \\
\hline RP-1 & 3.14 & 221.1 & $84.1,95.0$ \\
\hline RIS & 3.47 & 411.2 & 191.1 \\
\hline RP-2 & 3.81 & 427.2 & $191.1,235.1$ \\
\hline RP-3 & 4.07 & 411.2 & 191.1 \\
\hline VP-1 & 1.37 & 180.1 & 107.0 \\
\hline VP-2 & 1.56 & 210.1 & $121.1,137.1$ \\
\hline VP-3 & 2.03 & 196.1 & $121.1,148.1,162.1,178.1$ \\
\hline VP-4 & 2.12 & 180.1 & $121.1,148.1,162.1$ \\
\hline VP-5 & 2.20 & 194.1 & 121.1 \\
\hline VP-6 & 2.37 & 292.2 & $121.1,166.1,201.1,229.1,274.2$ \\
\hline VEN & 3.66 & 278.2 & $121.1,147.1,215.1,260.2$ \\
\hline $\mathrm{ZOP}$ & 3.01 & 389.1 & $99.1,112.0,217.0,245.0$ \\
\hline ZP-1 & 3.29 & 405.1 & $99.1,112.0,217.0,245.0$ \\
\hline $\mathrm{ZP}-2$ & 3.56 & 279.0 & $81.0,107.0,112.0,155.0,235.0$ \\
\hline $\mathrm{ZP}-3$ & 3.76 & 200.0 & $112.0,155.0$ \\
\hline ZP-4 & 3.81 & 278.1 & $81.0,107.0,147.1,172.1,260.1$ \\
\hline ZP-5 & 4.83 & 247.0 & $81.0,107.0,112.0,141.0,219.0$ \\
\hline ZP-6 & 5.35 & 235.0 & $81,0,107.0,112.0,155.0$ \\
\hline
\end{tabular}

\section{Standard solutions}

Calibration standard solutions of examined substances were prepared in methanol. Standard solutions were prepared in concentration ranges: AMI from 0.204 to $2.040 \mathrm{mg} \mathrm{cm}^{-3}$; DOX from 0.200 to $2.000 \mathrm{mg} \mathrm{cm}^{-3}$, HAL from 0.214 to $2.140 \mathrm{mg} \mathrm{cm}^{-3}$, RIS from 0.214 , to $2.140 \mathrm{mg} \mathrm{cm}^{-3}$, VEN from 0.204 to $2.040 \mathrm{mg} \mathrm{cm}^{-3}$, ZOP from 0.210 , to $2.100 \mathrm{mg} \mathrm{cm}^{-3}$.

\section{Irradiation conditions and preparation of samples}

On Petri dishes with a diameter of $5.7 \mathrm{~cm}, 30.0 \mathrm{mg}$ of the examined substances and powdered tablet formulation containing $30.0 \mathrm{mg}$ of active substance, was weighed. For each sample, dark control sample was prepared, which was protected from radiation by four layers of aluminum foil. 
The samples were inserted into the climatic chamber KBFICH 240 APT.line (Binder GmbH, Tuttlingen, Germany) and exposed to UVA irradiation. Irradiation was carried out under the following conditions: range of radiation $320-400 \mathrm{~nm}$ with maximum emission at $\lambda=365 \mathrm{~nm}$ at $20^{\circ} \mathrm{C}$ and relative humidity of $60 \%$. The samples were placed at a distance of $13 \mathrm{~cm}$ from the radiation source. Dose of emitted radiation was determined using VLX-3 radiometer (Vilber Lourmat) with CX-365 sensor and each time was $5.09 \cdot 10^{-3} \mathrm{~J} \mathrm{~cm} \mathrm{~min}^{-1}$. Every few days, the samples were thoroughly mixed. The exposure time of the samples was chosen experimentally. Irradiation was stopped when the degradation of the more labile samples reached about $30 \%$. After irradiation for a particular number of days, substances were dissolved in methanol and the powdered tablet formulation was extracted into methanol and centrifuged to obtain solutions at concentrations of approximately $1.00 \mathrm{mg} \mathrm{cm}^{-3}$. The obtained solutions were then analyzed by UHPLC-MS/MS method.

\section{UHPLC-MS/MS analysis}

The UHPLC-MS/MS system consisted of a Waters ACQUITY $^{\circledR}$ UPLC $^{\circledR}$ (Waters Corporation, Milford, MA, USA) coupled to a Waters TQD mass spectrometer (electrospray ionization mode ESI-tandem quadrupole). Chromatographic separations were carried out using the Acquity UPLC BEH (bridged ethyl hybrid) $\mathrm{C}_{18}$ column; $2.1 \times 100 \mathrm{~mm}$, and $1.7 \mu \mathrm{m}$ particle size, equipped with Acquity UPLC BEH C18 VanGuard pre-column; $2.1 \times 5 \mathrm{~mm}$, and $1.7 \mu \mathrm{m}$ particle size. The column was maintained at $40{ }^{\circ} \mathrm{C}$, and eluted under gradient conditions using from 95 to $0 \%$ of eluent A over $10 \mathrm{~min}$, at a flow rate of 0.3 $\mathrm{cm}^{3} \mathrm{~min}^{-1}$. Eluent A: $0.1 \% \mathrm{v} / \mathrm{v}$ formic acid in water; eluent B: $0.1 \% \mathrm{v} / \mathrm{v}$ formic acid in acetonitrile.

Chromatograms were recorded using Waters e $\lambda$ PDA detector. Compound concentration (\%i) after photodegradation was calculated by using the internal normalization method according to formula: $\% \mathrm{i}=A_{i} / \sum A \cdot 100 \%$, where $A_{i}$ is peak area of the constituent being determined, and $\sum A$ is the sum of peak areas for all constituents present in the chromatogram. Spectra were analyzed in $200-700 \mathrm{~nm}$ range with $1.2 \mathrm{~nm}$ resolution and sampling rate 20 points/s.

MS detection settings of Waters TQD mass spectrometer were as follows: source temperature $150{ }^{\circ} \mathrm{C}$, desolvation temperature $350{ }^{\circ} \mathrm{C}$, desolvation gas flow rate $600 \mathrm{dm}^{3} \mathrm{~h}^{-1}$, cone gas flow $100 \mathrm{dm}^{3} \mathrm{~h}^{-1}$, capillary potential $3.00 \mathrm{kV}$, cone potential $20 \mathrm{~V}$. Nitrogen was used for both nebulizing and drying gas. The data were obtained in a scan mode ranging from 50 to $1000 \mathrm{~m} / z$ in time $0.5 \mathrm{~s}$ intervals; 8 scans were summed up to get the final spectrum.

Collision activated dissociations (CAD) analyses were carried out with the energy of $30 \mathrm{eV}$, and all the fragmentations were observed in the source. Consequently, the ion spectra were obtained by scanning from 50 to $500 \mathrm{~m} / z$ range. Data acquisition software was MassLynx V 4.1 (Waters).

\section{Validation}

Validation of the method was performed by the determination of specificity, accuracy, precision, linearity, limit of detection, and limit of quantification [24].

Specificity of the method was assessed by comparing chromatograms of pure standards and chromatograms of tested solutions after the exposure to UVA radiation, taking into account retention time $\left(t_{\mathrm{R}}\right)$ and resolution factor $\left(R_{\mathrm{s}}\right)$ of peaks derived from the tested substances and neighboring peaks from degradation products.

Accuracy was determined based on sample analysis of known concentrations and comparing the results obtained by a validated method with true values, followed by calculation of the recovery percentage. Determinations were performed at three concentration levels: $80 \%, 100 \%$, and $120 \%$, for each of them three repetitions were done.

Precision of the method was determined at three levels of drug concentrations in reference solutions: $50 \%, 100 \%$, and $150 \%$. For each concentration level, three repetitions were done.

Evaluation of linearity was performed by plotting a curve between peak area and concentration of the tested substances. For each drug, two series of determinations were performed within the concentration ranges described in "Standard solutions" section.

Limit of detection and limit of quantification were determined from linearity in the concentration ranges: AMI from 0.204 to $1.224 \mathrm{mg} \mathrm{cm}^{-3}$, DOX from 0.200 to $1.200 \mathrm{mg} \mathrm{cm}^{-3}$, HAL from 0.214 to $1.284 \mathrm{mg} \mathrm{cm}^{-3}$, RIS from 0.214 to $1.284 \mathrm{mg} \mathrm{cm}^{-3}$, VEN from 0.204 to $1.224 \mathrm{mg} \mathrm{cm}^{-3}$, ZOP from 0.210 to $1.260 \mathrm{mg} \mathrm{cm}^{-3}$, using formulas: $\mathrm{LOD}=3.3 \cdot S_{\mathrm{y}} / a, \mathrm{LOQ}=10 \cdot S_{\mathrm{y}} / a$, where: $S_{\mathrm{y}}$ estimation error, $a-$ slope of the regression line.

Acknowledgements In memory of Professor Jan Krzek (19462015), Head of Department of Inorganic and Analytical Chemistry, Jagiellonian University, Medical College, Dean of Faculty of Pharmacy 2008-2015.

Open Access This article is licensed under a Creative Commons Attribution 4.0 International License, which permits use, sharing, adaptation, distribution and reproduction in any medium or format, as long as you give appropriate credit to the original author(s) and the source, provide a link to the Creative Commons licence, and indicate if changes were made. The images or other third party material in this article are included in the article's Creative Commons licence, unless indicated otherwise in a credit line to the material. If material is not included in the article's Creative Commons licence and your intended use is not permitted by statutory regulation or exceeds the permitted use, you will need to obtain permission directly from the copyright holder. To view a copy of this licence, visit http://creativecommons.org/licenses/by/4.0/. 


\section{References}

1. ICH (2003) Stability testing of new drug substances and products, Q1A (R2). ICH, Geneva

2. ICH (2003) Stability testing: photostability testing of new drug substances and products, Q1B. ICH, Geneva

3. Henry B, Foti C, Alsante K (2009) J Photochem Photobiol B Biol 96:57

4. Baertschi SW, Alsante KM, Tønnesen HH (2010) J Pharm Sci 99:2934

5. Baertschi SW, Clapham D, Foti C, Kleinman MH, Kristensen S, Reed RA, Templeton AC, Tønnesen HH (2013) J Pharm Sci 102:3888

6. Tønnesen HH, Hanne H (2004) Photostability of drugs and drug formulations, 2nd edn. CRC Press, Boca Raton

7. Skibinski R (2011) J Pharm Biomed Anal 56:904

8. Székely P, Gyéresi Á, Hancu G (2010) Acta Med Marisiensis $56: 460$

9. Székely P, Gyéresi Á, Hancu G, Laczkó Zöld E, Vencea SZ (2011) Acta Med Marisiensis 57:745

10. Asafu-Adjaye EB, Faustino PJ, Tawakkul MA, Anderson LW, Yu LX, Kwon H, Volpe DA (2007) J Pharm Biomed Anal 43:1854

11. Tonon MA, Bonato PS (2012) Electrophoresis 33:1606

12. Komsta L (2012) J AOAC Int 95:669

13. Girotti AW (1990) Photochem Photobiol 51:497
14. Jamrógiewicz M, Jasińska K, Sawicki W (2012) Farm Pol 68:858

15. Baran W, Adamek E, Makowski A (2008) Chem Eng J 145:242

16. Raffin RP, Colome LM, Schapoval EES, Pohlmann AR, Guterres SS (2008) Eur J Pharm Biopharm 69:1014

17. Dhurke R, Kushwaha I, Desai BG (2013) PDA J Pharm Sci Technol 67:43

18. Prakash Rao B, Rajarajan S, Monica A, Ramesh K, Beny B, Nagini KSS, Vijay Kumar Gupta N (2013) J Pharm Sci Res $5: 240$

19. Santos SS, Lorenzoni A, Ferreira LM, Mattiazzi L, Adams AIH, Denardi LB, Alves SH, Schaffazick SR, Cruza L (2013) Mater Sci Eng C Mater Biol Appl 33:1389

20. Kurmen JEC, Alvarez MIG, Rivero LFV (2015) Brazilian Arch Biol Technol 58:468

21. Villamizar L, Barrera G, Cotes AM, Martinez F (2010) J Microencapsul 27:314

22. Rabello MS, White JR (1996) Polym Compos 17:691

23. Deshmukh K, Kangda AR, Mahajan SP, Swamini C, Anupama K, Peshwe DR (2018) J Res Eng Appl Sci 3:1

24. ICH (2005) Validation of analytical procedures: text and methodology, Q2 (R1). ICH, Geneva

Publisher's Note Springer Nature remains neutral with regard to jurisdictional claims in published maps and institutional affiliations. 